\title{
Virtual Reality Training Software for Labor Accident Free Process in Construction
}

\author{
Viacheslav Burlov ${ }^{1 *}$, Anastasiya Uvarova $^{1}$, and Fedor Gomazov ${ }^{1}$ \\ ${ }^{1}$ Peter the Great St.Petersburg Polytechnic University, Polytechnicheskaya, 29, St.Petersburg, 195251, \\ Russia
}

\begin{abstract}
This paper presents a methodology for the formation of a VR training program for the safe conduct of work on a construction site. The based approach allowed us to identify the key elements of the work and create a mathematical model of a person's decision. The result of this work is the developed methodology for the use of virtual reality devices for teaching safe construction work based on solving the inverse problem.
\end{abstract}

\section{Introduction}

The construction industry provides the labor market with vacancies and provides employment to a significant number of specialists in various fields. At the same time, the activities related to the organization and conduct of construction work are quite laborintensive, lengthy, and dangerous, which leads to a high level of injuries and deaths on construction sites. [1,2] Only in St. Petersburg from 2016 to 2018, 69 serious accidents and 104 fatal accidents occurred. The main reason for such figures both in Russia and in the world is the lack of training of workers and management in issues related to labor protection and safe work. [3-5]

The use of modern tools, such as virtual reality devices, to train construction site workers to safely conduct work will significantly reduce the number of accidents on construction sites, which is important, given the growth forecasts of the construction industry. [6,7] The trend in the development of the sphere brings the work on modern training technologies and the management of the processes of ensuring the safety of construction works to the list of the most important needs of the modern world. [8,9]

The safety of the construction sector, due to its relevance, is considered from different sides. General approaches to safety training have been considered by many scientists [1013]. The main trend is the risk-based approach, which is an example of an analytical approach known from system engineering [14]. The theoretical basis of this study is an example of another approach - the synthesis-based approach. This approach was investigated by V. G. Burlov and successfully applied to various branches of security [1517].

The training of the employee in the safe conduct of work is the most important task of researchers in the field of construction safety $[18,19]$

\footnotetext{
*Corresponding author: burlov_vg@spbstu.ru
} 
The purpose of the study was to form the basic principles of building a training program for virtual reality devices to ensure the safety of work on a construction site using the example of a slinger.

\section{Methods}

The research was carried out based on a natural science approach to ensuring the safety of construction work. During the study, the law of preserving the integrity of the object was applied, which, in turn, is a repeated stable relationship between the properties of the object and the action, provided that the purpose is fixed. This law manifests itself in the mutual transformation of the properties of an object and an action.

The main activity in any field is the decision of a person (Fig. 1), this decision depends on the properties of the situation (objectivity, integrity, variability) and is considered at three levels of knowledge (methodological, methodological, and technological).

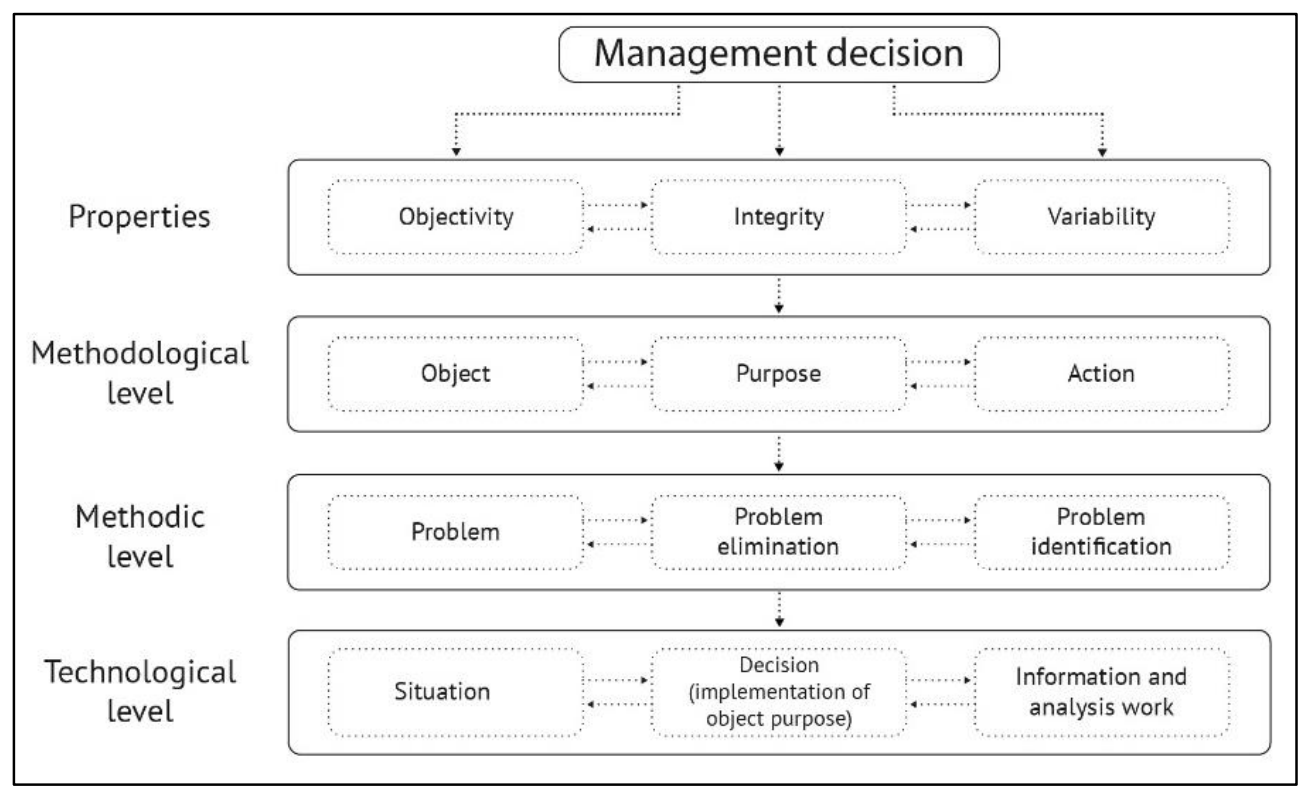

Fig. 1. Management decision.

While applying three basic methods of scientific research-decomposition, abstraction, and aggregation, a management decision model was synthesized (Fig. 2), based on three processes - the manifestation of the problem, the identification of the problem, and the neutralization of the problem. These processes depend on the situation (the time of the problem manifestation), the information and analytical work of the decision-maker (the time of the problem identification) and on the final solution (the time of the problem neutralization). 


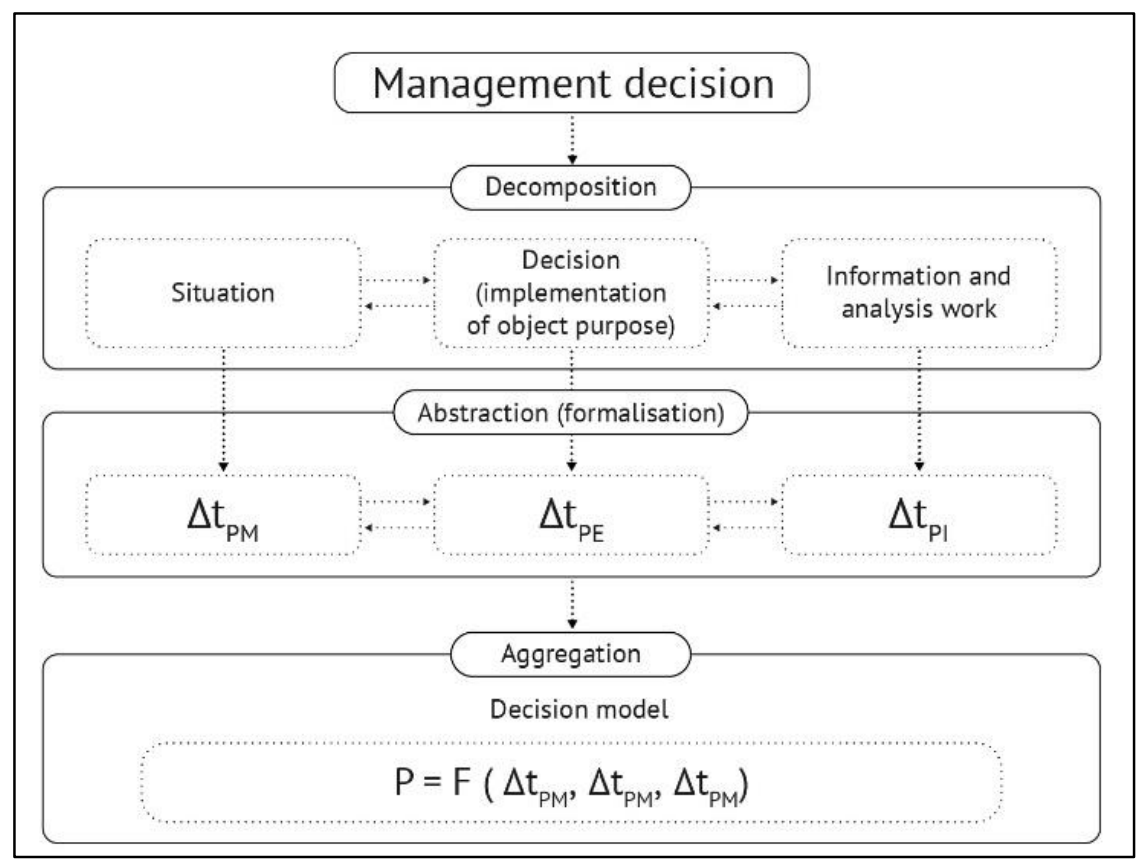

Fig. 2. Management decision model.

In the course of the work, the slinger's work on various construction sites was reviewed, after which key time indicators were identified and the network schedule was considered using the network planning method. These time indicators were proposed as a methodology for the formation of a VR training program.

\section{Results}

The management decision model depends on three basic processes. This model is shown in Fig. 3. The values $\lambda$, v1 and $\mathrm{v} 2$ are the intensity of the manifestation, identification, and neutralization of the problem, respectively. They are inversely proportional to the time spent on the corresponding actions.

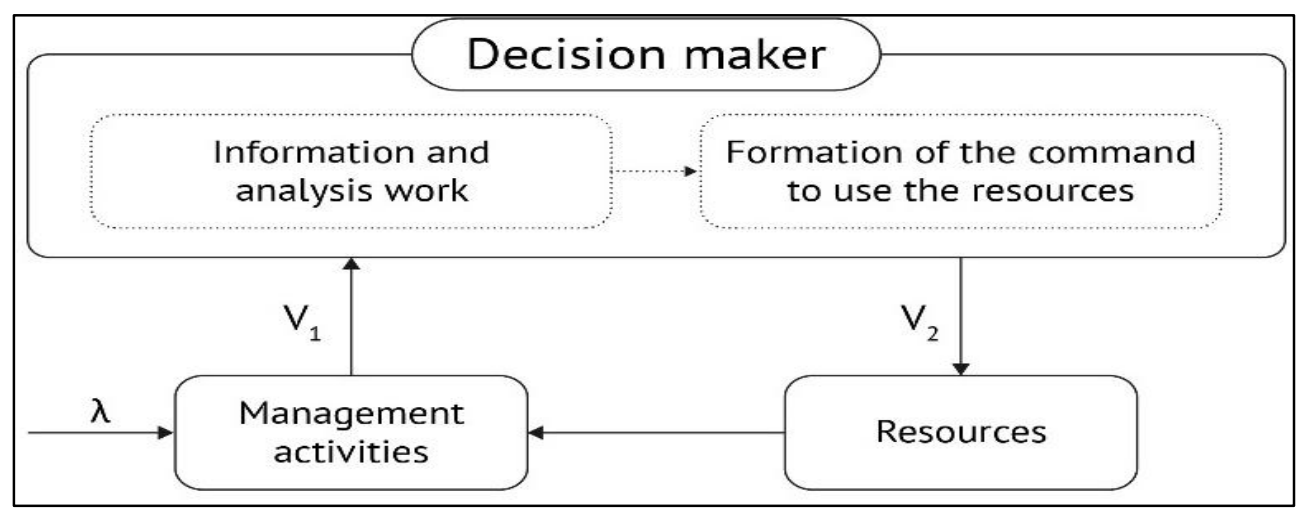

Fig. 3. Decision. 
The method of network planning applied to the work of the slinger allowed us to form and calculate the critical path of performing all actions and determine the time for identifying and neutralizing the problem.

\subsection{Development of a network model for problem identification}

The network model of problem identification was developed during the slinger's work study, which revealed the stages of work and the time spent on their implementation, because of which a critical way of identifying problems in the slinger's work was determined (Fig. 4).

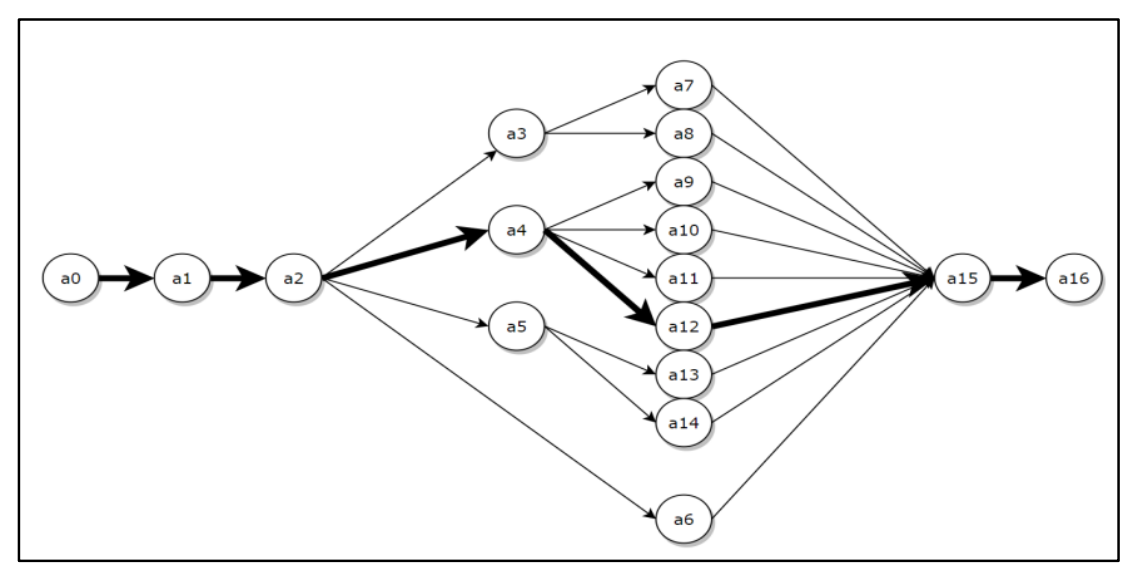

Fig. 4. Critical problem identification path.

The length of the critical path of problem identification was calculated by determining the working total time reserve is zero and was 64 minutes, which is the time of problem identification. This time is necessary to solve the inverse problem of managing and evaluating the safety indicator of the work on the binding of goods. The transition from the time required for problem identification to the intensity of problem identification allows us to use the system of Kolmogorov differential equations and calculate the intensity. The intensity calculation is represented by the (1).

$$
v_{1}=\frac{1}{64}=0,0156
$$

\subsection{Development of a network model for problem neutralization}

The ability to neutralize, that is, to eliminate problems while performing their official duties, is one of the key factors in the qualification of an employee. Neutralization of problems is possible only after their identification, and therefore, the main tasks of training a specialist are to reduce the time for identification and neutralization of problems, which increases the overall level of security. The network planning method allowed us to determine the critical way to neutralize the problem (Fig. 5). 


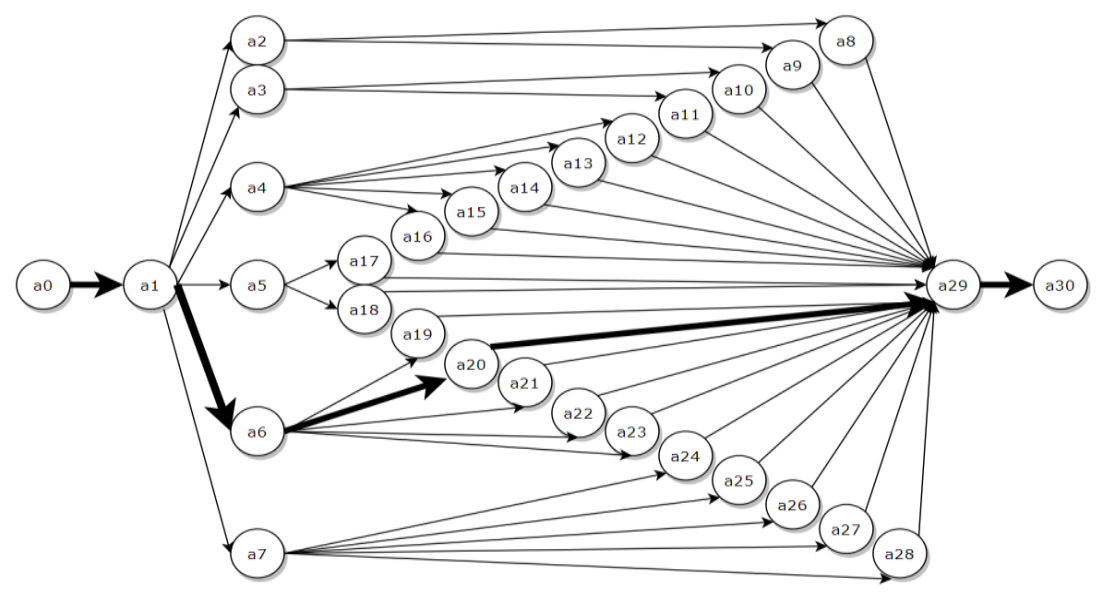

Fig. 5. Critical problem neutralization path.

The length of the critical path to neutralize the problem was calculated by determining the longest work whose total time reserve is zero and was 59 minutes, which is the time to neutralize the problem. This time is necessary to solve the inverse problem of managing and evaluating the safety indicator of the work on the binding of goods. The transition from the time required for problem identification to the intensity of problem identification allows us to use the system of Kolmogorov differential equations and calculate the intensity (2):

$$
v_{2}=\frac{1}{59}=0,0169
$$

The main problem of using virtual reality devices to train employees in the safe conduct of construction work is to understand the principle of modeling dangerous situations. [2021]

In other words, to develop a system, you need to understand what initial data should be included in the construction simulation program, what goals should be achieved by the worker in the training process, so that the training itself really affects the overall level of safety.

The study examined a case with four basic states (Figure 6).

- A00-the person does not identify the threat and does not neutralize it;

- A10-the person identifies the threat, but does not neutralize it;

- A01-the person does not identify the threat, but neutralizes it;

- A11-a person both identifies the threat and neutralizes it.

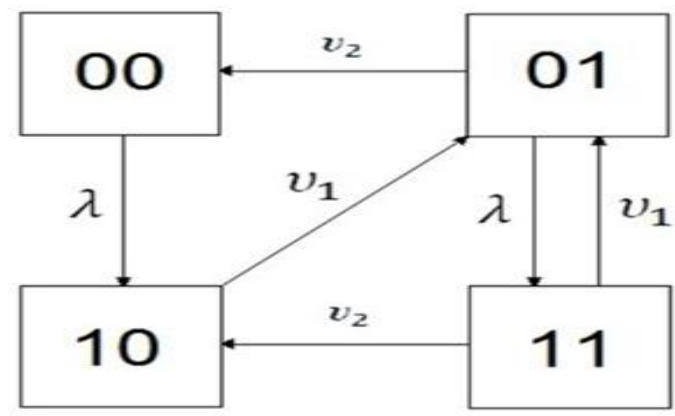

Fig. 6. Graph of the states of the process of forming a management decision. 
The solution of the Kolmogorov equation system for this graph (3) allowed us to determine the mathematical model of the human solution described in Figure 2. This model shows the probability of finding it at a time when the existing problem has already been solved, and a new one has not yet arrived:

$$
P_{00}=\frac{v_{1} v_{2}}{\lambda\left(\lambda+v_{1}+v_{2}\right)+v_{1} v_{2}}
$$

\section{Discussion}

The use of this model (3) allowed us to form an algorithm that can be used to create a training program for safe construction work for virtual reality devices.

1. The safety indicator P00 is set.

2. Based on the safety indicator, the requirements for the time of work execution are formed.

3. Also, based on the safety indicator, emergency situations are simulated at any of the work sites.

4. The employee trains in achieving the time indicators corresponding to the specified safety indicator.

5. If all time indicators are met, the safety indicator increases, and the training reaches a new level of complexity.

Such an algorithm for creating a training program allows, on the one hand, to work out skills in virtual reality and, on the other hand, to understand how the employee's actions and the speed of performing these actions affect the safety of the entire process.

Since the data were taken based on the real experience of the slinger of the construction organization, they correspond to the real situation. To develop a training program for the simulation of the working process, it is necessary to provide reduced time indicators to optimize the training process of the employee. Then, based on the specified safety indicator, it will be possible to mark the time indicators of the training process, considering the reduction in the total time amount.

\section{Conclusion}

The technology of training in the safe conduct of construction work using virtual reality devices has a huge potential, since it significantly increases the number of possible potentially dangerous situations on the construction site that can be worked out in conditions close to reality. Also, such devices are currently at the peak of technological progress and have fundamentally new characteristics and opportunities for expanding the educational process.

\section{References}

1. S. P. Breloff, Dutta, A., Dai, F., Sinsel, E. W., Warren, C. M., Ning, X., \& Wu, J. Z. (2019). Assessing work-related risk factors for musculoskeletal knee disorders in construction roofing tasks. Applied Ergonomics, 81.

2. A. Setiawan, Akbar, S. R., Istambul, M. R., Agustian, Y., \& Saudi, M. H. B. M. (2019). Effect of work safety and health knowledge on construction workers in cawang-tomang cengkareng toll road projects. Civil Engineering and Architecture, $7(3)$. 
3. T. Kaverzneva, Tarkhov, D., Uljanov, A., Senchenko, V., Pshenichnaya, C., \& Alibekova, I. (2019). Criteria for ensuring acoustic safety in the assembly shops of machine-building enterprises. Paper presented at the IOP Conference Series: Materials Science and Engineering, , 643(1) doi:10.1088/1757-899X/643/1/012119

4. O. A. Gubanova, Ivanov, A. Y., Krutolapov, A. S., Pelekh, M. T., \& Gubanova, J. A. (2018). Reasons for the information processes utilization in the era of the platform industry 4.0. International Journal of Civil Engineering and Technology, 9(12), 43-47.

5. B. Zhong, Pan, X., Love, P.E.D., Ding, L., Fang, W. Deep learning and network analysis: Classifying and visualizing accident narratives in construction (2020). Automation in Construction, 113, paper № 103089.

6. M. Hafsia, Monacelli, E., Martin, H. Virtual reality simulator for construction workers (2018). ACM International Conference Proceeding Series.

7. E. Boltyonkova, Andreev, A., \& Doronin, A. (2019). Development of measures to ensure information security in structural division of the university. Paper presented at the E3S Web of Conferences, , 140 doi:10.1051/e3sconf/201914008005

8. O. Golovina, Kazanci, C., Teizer, J., König, M. Using serious games in virtual reality for automated close call and contact collision analysis in construction safety (2019) Proceedings of the 36th International Symposium on Automation and Robotics in Construction, ISARC 2019, pp. 967-974.

9. Abdul Aziz, F., Alsaeed, A.S.M.A., Sulaiman, S., Ariffin, M.K.A.M., Al-Arhabi, A.R.Y. Virtual Reality Training Platform in Onshore Pipeline (2020) Lecture Notes in Mechanical Engineering, pp. 207-216.

10. D. Y. Zakharov, Klimova, I. V., Remishevskaya, K. V., \& Tokareva, S. A. (2019). Calculation of the escalation probability as a solution to the inverse problem of predicting the reliability of the man-machine systems. Bezopasnost' Truda $\mathrm{v}$ Promyshlennosti, 2019(11), 54-59. doi:10.24000/0409-2961-2019-11-54-59

11. K. Pykhtin, Simankina, T., Sharmanov, V., \& Kopytova, A. (2017). Risk-based approach in valuation of workplace injury rate for transportation and construction industry. Paper presented at the IOP Conference Series: Earth and Environmental Science.

12. M. O. Sanni-Anibire, Mahmoud, A. S., Hassanain, M. A., \& Salami, B. A. (2020). A risk assessment approach for enhancing construction safety performance. Safety Science, 121, 15-29.

13. E. Sugak, (2018). Methodological and organizational problems of professional risk management in construction. MATEC Web of Conferences.

14. H.H. Goode, Machol, R.E., 1957. System engineering: an introduction to the design of large-scale systems. McGraw-Hill Book Co. New York

15. V. Burlov, Andreev, A., \& Gomazov, F. (2018). Mathematical model of human decision - A methodological basis for the realization of the human factor in safety management. Paper presented at the Procedia Computer Science, , 145 112-117. doi:10.1016/j.procs.2018.11.018

16. V. G. Burlov, Grobitski, A. M., \& Grobitskaya, A. M. (2016). Construction management in terms of indicator of the successfully fulfilled production task. Magazine of Civil Engineering, 63(3), 77-91. doi:10.5862/MCE.63.5

17. V. G. Burlov, Gomazov, F. A., \& Uvarova, A. O. (2018). Technology for managing the processes of ensuring labor safety at municipal waste processing enterprises. Paper presented at the Proceedings of the 2018 IEEE International Conference "Management 
of Municipal Waste as an Important Factor of Sustainable Urban Development", WASTE 2018, 82-85. doi:10.1109/WASTE.2018.8554168

18. K. Kang, \& Ryu, H. (2019). Predicting types of occupational accidents at construction sites in korea using random forest model. Safety Science, 120, 226-236..

19. S. R. Mohandes, \& Zhang, X. (2019). Towards the development of a comprehensive hybrid fuzzy-based occupational risk assessment model for construction workers. Safety Science, 115, 294-309.

20. M. Nykänen, Puro, V., Tiikkaja, M., Kannisto, H., Lantto, E., Simpura, F., Uusitalo, J., Lukander, K., Räsänen, T., Teperi, A.-M. Evaluation of the efficacy of a virtual realitybased safety training and human factors training method: Study protocol for a randomised-controlled trial (2019) Injury Prevention.

21. R.P. Zhang, Cheung, C.M., Lei, H. Applications of visualisation technology in construction safety training: A preliminary review (2019) Association of Researchers in Construction Management, ARCOM 2019 - Proceedings of the 35th Annual Conference, pp. 396-405. 